\title{
Diagnostic utility of absolute neutrophil count as a new marker of spontaneous bacterial peritonitis; multicenter study
}

Nasser Mousa ( $\square$ mousa_medic@yahoo.com )

Mansoura University

Ahmed Abdel-Razik

Mansoura University

Tarek Sheta

Mansoura University

Ahmed Deiab

Mansoura University

Khaled Taha

Mansoura University

Rasha Mahmoud

Mansoura University

Ahmed Yassen

Mansoura University

Alaa Habib

Mansoura University

Amany Amer

Menoufia University

Eman Mousa

Mansoura University

Niveen El-Wakeel

Mansoura University

Amr El-Sabbagh

Mansoura University

Mohmoud Awad

Mansoura University

Muhammad Diasty

Mansoura University

Aya Fathy

Mansoura University

Ola El-Emam 
Mansoura University

Mostafa Abdelsalam

Mansoura University

Ayman Elgamal

Mansoura University

Sherif Elbaz

Aswan University

\section{Essam Elmahdi}

Mansoura University

Dina Elhammady

Mansoura University

\section{Research Article}

Keywords: Ascites, spontaneous bacterial peritonitis, absolute neutrophil count, $\mathrm{C}$ reactive protein, bacterial peritonitis, and liver cirrhosis.

Posted Date: February 15th, 2022

DOl: https://doi.org/10.21203/rs.3.rs-1331927/v1

License: (c) (i) This work is licensed under a Creative Commons Attribution 4.0 International License. Read Full License 
$4 \quad$ Nasser Mousa ${ }^{1,2}$, Ahmed Abdel-Razik $^{1}$, Tarek Sheta ${ }^{3}$, Ahmed Deiab $^{3}$, Khaled Taha ${ }^{3}$, 5 Rasha Mahmoud $^{3}$, Ahmed Yassen ${ }^{1}$, Alaa Habib ${ }^{3}$, Amany Amer ${ }^{4}$, Eman Mousa ${ }^{5}$, Niveen 6 El-Wakeel $^{6}$, Amr El-Sabbagh ${ }^{6}$, Mohmoud Awad ${ }^{3}$, Muhammad Diasty ${ }^{1}$, Aya Fathy ${ }^{7}$, Ola $7 \quad$ El-Emam $^{8}$, Mostafa Abdelsalam $^{9}$, Ayman Elgamal $^{4}$, Sherif Elbaz $^{10}$, Essam Elmahdi $^{3}$

\section{Diagnostic utility of absolute neutrophil count as a new marker of spontaneous bacterial peritonitis; multicenter study} ,Dina Elhammady ${ }^{1}$.

${ }^{1}$ Tropical Medicine Department, Mansoura University, Mansoura, Egypt.

2 Hepatology and Gastroentrology Unit, Damietta Cardiology and Gastroenterology Center, Damietta, Egypt.

${ }^{3}$ Internal Medicine Department, Mansoura University, Mansoura Egypt.

${ }^{4}$ Department of Tropical Medicine, Menoufia University, Menoufia, Egypt.

${ }^{5}$ Faculty of Dentistry, Mansoura University, Mansoura, Egypt.

${ }^{6}$ Medical Microbiology and Immunology, Mansoura University, Mansoura, Egypt.

${ }^{7}$ Public Health and Community Medicine, Mansoura University, Mansoura, Egypt.

${ }^{8}$ Clinical Pathology Department, Mansoura University, Mansoura, Egypt.

${ }^{9}$ Nephrology and Dialysis Unit, Internal Medicine Department, Faculty of Medicine, Mansoura University, Mansoura, Egypt.

${ }^{10}$ Endemic Diseases and Gastroenterology Department, Aswan University, Aswan, Egypt Corresponding author: Prof: Nasser Mousa, MD Tropical Medicine, Faculty of medicine. Mansoura University, Egypt. Mobile: 00201227029213-00201024501181.

3 E-mail.mousa_medic@yahoo.com 
27 Abstract.

28 background. Spontaneous bacterial peritonitis (SBP) is a fatal complication of liver 29 cirrhosis with high mortality rates.

30 Objective: The aim of this study is to investigate the diagnostic utility of absolute neutrophil count (ANC) as a non-invasive marker for SBP diagnosis.

32 Methods. Six hundred patients with cirrhotic ascites were included in the study. All 33 patients underwent abdominal paracentesis and the ascitic fluid was processed for cell 34 count and culture.

35 Results. Absolute neutrophil count was significantly higher in SBP versus non-SBP and 36 in culture positive SBP versus culture negative SBP. ANC at cutoff value > 2.804 has $3784 \%$ sensitivity and $78 \%$ specificity for diagnosis of SBP with positive and negative 38 predictive values ( $79.4 \%$ and 83.6 respectively). At a cut-off point $>5.6$, ANC is capable 39 of differentiating culture positive SBP from culture negative SBP cases with 62.07\% 40 sensitivity and $60.87 \%$ specificity. Increased ANC, white blood cell (WBC), C reactive 41 protein (CRP), creatinine and decreased platelet emerged as independent risk factors for 42 SBP development, while increased ANC, WBC and decreased platelets were independent 43 predictors of culture positive SBP.

44 Conclusion. This study demonstrates that, ANC count is simple, non-invasive diagnostic 45 marker for SBP. Increased ANC, WBC, CRP, creatinine and decreased platelet emerged 46 as independent risk factors for SBP development.

47 Keywords. Ascites, spontaneous bacterial peritonitis, absolute neutrophil count, C 48 reactive protein, bacterial peritonitis, and liver cirrhosis. 


\section{Introduction}

56 Ascites is a serious complication of decompensated liver cirrhosis. Although many 57 pathogenic processes have been implicated in the development of ascites, about $75 \%$ 58 likely occur as a result of portal hypertension in the setting of liver cirrhosis with the 59 remainder due to infectious, inflammatory and infiltrative conditions. ${ }^{1-6}$ In cirrhotic 60 patients, bacterial infection increases the morbidity and mortality. ${ }^{7-9}$ Spontaneous 61 bacterial peritonitis (SBP) is a risky complication that occurs amongst cirrhotic patients 62 with ascites. SBP develops in approximately 10 to $30 \%$ of cirrhotic patients. ${ }^{10}$ The 63 mortality rate in patients with spontaneous bacterial peritonitis ranges from 40-70\% with 64 hospital-mortality rate about 20\%. However, nowadays the mortality from 65 spontaneous.bacterial peritonitis may be decreasing because of advances in its diagnosis 66 and treatment ${ }^{11,12} \mathrm{SBP}$ results from qualitative and quantitative alterations in microbiota 67 of the gut, bacterial translocation and increased permeability of the intestine ${ }^{12}$. 68 Additionally, the impairment of the immune system observed in advanced cirrhotic 69 patients plays an important role. ${ }^{13}$ The significance of SBP is mainly due to the late onset 70 of symptoms, high rate of recurrence and the multiple causative organisms. ${ }^{14-16}$ The blood 71 neutrophil count have diagnostic utilities in evaluation of severity and intensive care unit 72 admission of many types of infection including SBP. ${ }^{17}{ }^{18}$ Serum CRP is synthesized

73 mainly in liver cell under the control of many cytokines produced by macrophages at the 74 time of bacterial infection. ${ }^{19}$

75 Although many non-invasive and invasive markers were studied as diagnostic tools for $76 \mathrm{SBP}^{20-24}$, the diagnosis of SBP remains based on diagnostic paracentesis. However, 77 diagnostic paracentesis is an invasive maneuver with many complications such aswound 78 infection, abdominal wall hematoma, spontaneous hemoperitoneum that necessitating 79 other non-invasive diagnostic tools.

80 Therefore, the aim of this study is to evaluate the clinical utility of absolute 81 neutrophil count as a novel, simple, cheap, and noninvasive biochemical test for 82 diagnosis of SBP.

\section{Patients and methods}

84 In this prospective study, we recruited 600 patients with liver cirrhosis and ascites 85 referred to Tropical and Internal Medicine Departments, Mansoura University, 
Department of Tropical Medicine, Menoufia University, and Damietta Cardiology and

87 Gastroenterology Center from October 2018 to Jun 2020. All patients were subjected to complete history taking and physical examination include, abdominal ultrasonography and triphasic CT when indicated. The exclusion criteria were non-cirrhotic ascites (e.g. malignant ascites, tuberculus ascites), immunocompromised patients, and patients who had taken antibiotics prior to hospital admission or on prophylactic antibiotics for SBP or on anticoagulant medications. Furthermore, patients with heart or renal failure, neoplastic

93 disorders, hematological disorders, clinically evident autoimmune disorders, secondary bacterial peritonitis due to any surgical causes and patients with unrelated infection that may influence the levels of blood WBC, e.g. skin and lung infection, were also excluded.

\section{Sampling}

97 1- The ascitic fluid samples $(15 \mathrm{ml})$ were aspirated under the complete aseptic condition 98 at the bedside, using the standard paracentesis technique. Ten ml was immediately 99 inoculated in bedside aerobic and anaerobic blood culture bottles. The remaining amount of ascitic fluid was sent for biochemical and cytological examination in tubes containing EDTA and analyzed within $3 \mathrm{~h}$ of aspiration. ${ }^{25}$ Ziehl-Neelsen staining of the ascitic fluid was done when needed.

Regarding microbiological examination, inoculated blood culture bottles were incubated for 3 successive days at $37^{\circ} \mathrm{C}$ with daily subculture on blood, MacConkey and chocolate agars. Antimicrobial susceptibility testing and bacterial identification were carried out using standard procedures.

According to international guidelines, SBP was diagnosed if the polymorph nuclear neutrophil (PMN) cell count in the ascitic fluid is $\geq 250 / \mathrm{mm} 3$ with positive culture of ascitic fluid (culture positive SBP) or culture negative neutrocytic ascites (CNNA) with PMN $>250 / \mathrm{mm}^{3}$ and a negative ascitic fluid culture in the absence of other causes of peritonitis and hemorrhagic ascites. ${ }^{26,27}$ Patients with ascitic fluid PMN cell count $<250$ cells/mm3 and a culture-negative ascitic fluid were assigned as the control group. 2. At the time of paracentesis, five $\mathrm{ml}$ of venous blood was withdrawn; one $\mathrm{ml}$ in 
115 clot. Non-hemolyzed sera were separated by centrifugation and used for determination of

116 liver functions (ALT, AST, and albumin bilirubin and prothrombin time) blood sugar,

117 creatinine, urea, alpha-fetoprotein and carcinoembryonic antigen. CRP was measured by

118 particle-enhanced immunoturbidimetric assay (C-reactive protein (Roche Diagnostics).

119 Blood absolute neutrophil count was calculated automatically using the CELL-DYN

120 Emerald cell counter (Abbott, Wiesbaden, Germany).

121 This study was performed with the approval of the Mansoura Faculty of Medicine 122 Institutional Review Board “MFM-IRB”.All patients provided written informed consent 123 prior to participation in any protocol-specific procedure.

\section{Statistical analysis}

125 Data were analyzed with SPSS version 21. The normality of data was first tested with 126 one-sample Kolmogorov-Smirnov test. Qualitative data were described using numbers 127 and percentage. Association between categorical variables was tested using Chi-square. 128 Continuous variables were presented as mean \pm SD (standard deviation) for parametric 129 data, but Median and IQR was used for non-parametric data. The two groups were 130 compared with Student t test (parametric data) and Mann-Whitney test (non-parametric 131 data). Clinical variables were considered statistically significant when $(\mathrm{p}<0.05)$. 132 Sensitivity and specificity of absolute neutrophil count for SBP diagnosis were estimated 133 by receiver operator characteristic curve. Significant parameters in univariate binary 134 logistic regression analysis were entered into a stepwise multivariate logistic regression 135 analysis to identify the independent predictors for the occurrence of SBP and culture 136 positive SBP.

137 Results

138 Table 1 shows the clinical, laboratory and demographic details of the studied groups. The 139 two groups were matched for age, sex and etiology of cirrhosis (viral hepatitis, NASH 140 and cryptogenic cirrhosis). Significant differences were found between both groups as 141 regards, fever, abdominal pain, bilirubin, AST, ALT, creatinine, prothrombine time (PT), 142 CRP, platelet count, blood WBC, ANC. No significant differences were found in serum 143 albumin, blood lymphocyte and hemoglobin. 
144 To determine predictive parameters for the diagnosis of SBP, variables with significant 145 associations on univariate analysis were subjected to a logistic regression analysis. 146 Increased ANC, WBC, CRP and creatinine and decreased platelets were independent 147 predictors of SBP development (Table 2).

148 Among the 300 patients with SBP, 184 (61.3\%) patients were culture positive SBP and $149116(38.6 \%)$ were culture negative SBP. No significant differences were found between 150 both groups regarding, abdominal pain, fever, albumin, bilirubin, AST, ALT, INR, blood 151 lymphocyte and haemoglobin. There was a significant increase in age and platelet count 152 in patients with culture-negative compared to culture-positive SBP. A significant increase 153 in, serum creatinine, CRP, blood WBC, blood neutrophil count was found in patients 154 with culture-positive SBP vs. culture-negative SBP (Table 3).

155 To determine reliable predictive parameters for the diagnosis of culture positive SBP, 156 variables with significant associations on univariate analysis were subjected to a logistic 157 regression analysis. Decreased platelets and increased ANC and WBC and were 158 independent predictors of culture positive SBP (Table 4).

The ROC curve analysis demonstrated that, absolute blood neutrophil count at a cut-off value of $>2.804$ had $84 \%$ sensitivity and $78 \%$ specificity for diagnosis of SBP with $16179.4 \%$ PPV, 83.6\% NPV and AUC equal to 0.88. (Figure 1). At cut-off point > 5.6, 162 absolute neutrophil count was capable of differentiating culture positive from culture 163 negative SBP cases with $62.07 \%$ sensitivity and $60.87 \%$ specificity with an AUC equal 164 to 0.59. (Figure 2).

\section{Discussion}

166 In the present study, we investigated the use of absolute blood neutrophil count as a 167 noninvasive diagnostic test for spontaneous bacterial peritonitis in cirrhotic ascitic 168 patients. The advantages of this test are simple, low cost and reliability. It is known that, 169 white blood cells (leukocytes) are a defense line against bacterial infection. The most 170 abundant leukocytes are neutrophil, which are the first line of defense against microbial 171 invasion. ${ }^{28}$ Moreover, absolute neutrophil count can be used as a predictive factor for 
172 infections. ${ }^{29}$ In general, bacterial infection is suspected if neutrophil in the blood are 173 increased. ${ }^{30}$

174 The diagnostic utility of the absolute neutrophil count for the diagnosis of spontaneous 175 bacterial peritonitis is rarely found in research. Our study showed that, absolute 176 neutrophil count is significantly higher in patients with spontaneous bacterial peritonitis 177 versus non-SBP patients. In addition, absolute neutrophil count at a cut-off point $>2.804$ 178 is capable of differentiating spontaneous bacterial peritonitis from non-SBP with $84 \%$ 179 sensitivity and 78\% specificity with positive and negative predictive values of $79.4 \%$ and 83.6 respectively and AUC equal to 0.88 .

181 The diagnostic utility of the blood neutrophil count as non-invasive test for the diagnosis 182 of several infections has been previously suggested. ${ }^{31-34}$ Mousa et al. evaluated the 183 clinical utility of combined blood neutrophil to lymphocyte ratio (NRL) and C-reactive 184 protein (CRP) as non-invasive tests for diagnosis of spontaneous bacterial peritonitis and 185 concluded that, NRL was significantly higher in spontaneous bacterial peritonitis versus 186 non-SBP, in addition, for SBP diagnosis, a blood NLR of $>2.89$ had a sensitivity of $18780.3 \%$ and a specificity of $88.9 \% .{ }^{33}$

188 Many laboratory tests have been introduced as predictive parameters for SBP, including 189 CRP level, platelet count, impaired prothrombin time and serum creatinine level. ${ }^{33,35,36}$ In 190 this study, logistic regression analysis demonstrated that, increased blood neutrophil, 191 WBC CRP and creatinine and decreased platelets were independent predictors of SBP 192 development.

193 Even with the use of sensitive methods, ascites culture is negative in nearly $60 \%$ of 194 patients with clinical manifestations suggestive of SBP and increased ascites neutrophil 195 count. ${ }^{37}$ As culturing bacteria needs time, delays in antibacterial treatment can be fatal and 196 result in the death of the patient from overwhelming infection. Mousa et al, in his study 197 found no significant difference in patients with culture-positive SBP versus culture198 negative SBP regarding NLR. ${ }^{33}$ However, in our study, we found that, absolute 199 neutrophil count is significantly higher in culture positive SBP versus culture negative 200 SBP and at a cut-off point $>5.6$, neutrophil count is capable of differentiating culture 201 positive from culture negative SBP cases with $62.07 \%$ sensitivity and $60.87 \%$ 202 specificity with an AUC equal to 0.59. 
In this study, logistic regression analysis demonstrated that, increased blood absolute

204 neutrophil, WBC, CRP and decreased platelet count were independent predictors for 205 culture positive SBP. Schwabl et al in his study found that, WBC were elevated in 206 patients presenting with SBP versus cirrhotic ascitic patients without SBP. ${ }^{36}$

207 Conclusion. Based on current evidence, the absolute blood neutrophil count, which 208 requires only routine laboratory test could be used as a new, simple, cheap, non-invasive 209 test for SBP diagnosis allowing rapid diagnosis and treatment of SBP so that reducing its 210 complications.

211 Acknowledgements. The authors would like to express their appreciation for all staff in 212 Tropical and Internal Medicine Departments, Mansoura University, Department of 213 Tropical Medicine, Menoufia University, and Damietta Cardiology and Gastroenterology 214 Center.

215 List of abbreviations.

216 SBP, spontaneous bacterial peritonitis; ANC, absolute neutrophil count; WBC, white 217 blood cell; CRP, C reactive protein; PMN polymorph nuclear neutrophil; CNNA, culture 218 negative neutrocytic ascites.

219 Declaration

220 Ethical Approval. This study was performed with the approval of the Mansoura Faculty of 221 Medicine Institutional Review Board "MFM-IRB”.

222 Consent to participate. All patients provided written informed consent prior to 223 participation in any protocol-specific procedure. All authors approve the publication of 224 this work.

225 Availability of data and materials. Not applicable

226 Competing interests. The authors declare that they have no competing interests.

227 Funding. we have no funding

228 Authors' contributions.

229 Nasser Mousa, Ahmed Abdel-Razik, Tarek Sheta, developed the original idea and 230 the protocol; Ahmed Deiab, Khaled Taha, Rasha Mahmoud, Ahmed Yassen, Alaa 231 Habib analyzed data; Mohmoud Awad, Amany Amer, Eman Mousa, wrote the 232 main manuscript text ; Niveen El-Wakeel, Amr El-Sabbagh, Narmen effat and Ola 233 El-Emam, done laboratory work; Muhammad Diasty, Aya Fathy statistical 
234 analysis; Mostafa Abdelsalam, Dina Elhammady, Ayman Elgamal prepared

235 figures, Sherif Elbaz, Essam Elmahdi revision of manuscript.

236

237

238

239

240

241

242

243

244

245

246

247

248

249

250

251

252

253

254

255

256

257

258

259

260

261

262

263

264 


\section{References}

266 1. Ripoll C, Groszmann R, Garcia-Tsao G, Burroughs A, Planas R, Escorsell A, et al.

267 Hepatic venous pressure gradient predicts clinical decompensation in patients with 268 compensated cirrhosis. Gastroenterology 2007;133 (2):481-488.

269 2. Elhadidy A, Farid K. Eosinophilic ascites: Uncommon Presentation of Eosinophilic 270 Gastroente- ritis in children. Med J Viral Hepatitis 2019; 3 (2) - pp. 37-40.

271 3. Pericleous M, Sarnowski A, Moore A, Fijten R, Zaman M. The clinical management of 272 abdominal ascites, spontaneous bacterial peritonitis and hepatorenal syndrome: a review 273 of current guidelines and recommendations. Eur J Gastroenterol Hepatol 2016; 274 28(3):e10-18.

275 4. ElmoghazyM, El Shabrawi A and Mousa N. Portal Hypertension, an Overview. Med 276 J Viral Hepatitis 2019;4 (1): 15-21.

277 5. Lucena MI, Andrade RJ, Tognoni G, Hidalgo R, De La Cuesta FS. Multicenter 278 hospital study on prescribing patterns forprophylaxis and treatment of complications of 279 cirrhosis. Eur J Clin Pharmacol 2002; 58:435-40.

280 6. Ibrahim I, Elbadrawy E, Nasr D. Frequency and characterization of mixed ascites 281 among cirrhotic patients admitted to Zagazig University hospital. Med J Viral 282 Hepatitis2020;4 (2): 75-80.

283 7. Arvaniti V, D’Amico G, Fede G, Manousou P, Tsochatzis E, Pleguezuelo M. 284 Infections in patients with cirrhosis increase mortality four-fold and should be used in 285 determining prognosis. Gastroenterology 2010;139: 1246-1256.

286 8. El Shabrawi A, Mohammed Abdelaziz A, Mousa N. Infections in cirrhotic patients. 287 Med J Viral Hepatitis 2019; 4 (1) - pp. 5-14.

288 9. Elbatae H, Ahmed Abdel-Razik A, Mousa E. Periodontal disease as predictor of 289 chronic liver diseases. Med J Viral Hepatitis 2020; 4 (2):57-61.

290 10. Bonnel AR, Bunchorntavakul C, Reddy KR. Immune dysfunction and infections in 291 patients with cirrhosis. ClinGastroenterolHepatol 2011;9:727-738.

292 11. Mandorfer M, Bota S, Schwabl P, Bucsics T, Pfisterer N, Kruzik M,et al. 293 Nonselective $B$ blockers increase risk for hepatorenal syndrome and death in patients with 294 cirrhosis and spontaneous bacterial peritonitis. Gastroenterology. 2014 Jun. 146(7):1680$29590 . \mathrm{e}$ 
297 12. Amr S, Ahmed A, Hoda E. Spontaneous Bacterial Peritonitis: An Overview. Med J 298 Viral Hepatitis 2018; 3 (1) - pp. 13-17.

299 13. Jalan R, Fernandez J, Wiest R, Schnabl B, Moreau R, Angeli P. Bacterial infections 300 in cirrhosis: a position statement based on the EASL Special Conference 2013. J Hepatol $301 \quad 2014 ; 60: 1310-1324$.

302 14. Garcia-Tsao G. Current Management of the Complications of Cirrhosis and Portal 303 Hypertension: Variceal Hemorrhage, Ascites, and Spontaneous Bacterial Peritonitis. Dig 304 Dis2016;34 (4): 382-386.

305 15. Lutz P, Nischalke HD, Strassburg CP, Spengler U. Spontaneous bacterial peritonitis:

306 The clinical challenge of a leaky gut and a cirrhotic liver. World J Hepatol 2015;7 (3): $307 \quad 304-314$.

308 16. Fernández J, Bert F, Nicolas-Chanoine MH. The challenges of multi-drug-resistance 309 in hepatology. J Hepatol 2016;65(5):1043-1054.

310 17. Lee JH, Song S, Yoon SY, Lim CS, Song JW, Kim HS. Neutrophil to lymphocyte 311 ratio and platelet to lymphocyte ratio as diagnostic markers for pneumonia severity. $\mathrm{Br} J$ 312 Biomed Sci 2016;73(3):140-142.

313 18. Iliaz R, Ozpolat T, Baran B, Demir K, Kaymakoglu S, Besisik F. Predicting mortality 314 in patients with spontaneous bacterial peritonitis using routine inflammatory and 315 biochemical markers. Eur J Gastroenterol Hepatol 2018;30(7):786-791.

316 19. Strauss E, de Sá Ribeiro MDFG. Bacterial infections ssociated with hepatic 317 encephalopathy: prevalence and outcome. Ann Hepatol. 2003;2:41-50.

318 20. Abdel-Razik A, Mousa N, Elbaz S, Eissa M, Elhelaly R, Eldars W. Diagnostic utility 319 of interferon gamma-induced protein $10 \mathrm{kDa}$ in spontaneous bacterial peritonitis: single320 center study. Eur J Gastroenterol Hepatol 2015;27(9):1087-1093.

321 21. Lee SS, Min HJ, Choi JY, Cho HC, Kim JJ, Lee JM, et al. Usefulness of ascitic fluid 322 lactoferrin levels in patients with liver cirrhosis.BMC Gastroenterol 2016;13;16(1):132.

323 22.Su DH, Zhuo C, Liao K, Cheng WB, Cheng H, Zhao XF. Value of serum 324 procalcitonin levels in predicting spontaneous bacterial 325 peritonitis.Hepatogastroenterology 2013;60(124):641-6. 
326 23. Luo J, Wu X, Zhang Y, Huang W, Jia B. Role of ascitic prostaglandin E2 in diagnosis

327 of spontaneous bacterial peritonitis and prediction of in-hospital mortality in patients with 328 decompensated cirrhosis.Medicine (Baltimore) 2019;98(26):e16016.

329 24. Abdel-Razik A, Mousa N, Abdel-Aziz M, Elsherbiny W, Zakaria S, Shabana W, et al. 330 Mansoura simple scoring system for prediction of spontaneous bacterial peritonitis: 331 lesson learnt. Eur J Gastroenterol Hepatol 2019;31(8):1017-1024.

332 25. Nasser Mousa, Sahar Zakaria, Mohamed Abd EL Maksoud. The Predictive Factors 333 for Recurrence of Spontaneous Bacterial Peritonitis. Med J Viral Hepatitis2018; 2 (2) 334 pp. 25-29.

335 26. EASL Clinical Practice Guidelines for the management of patients with 336 decompensated cirrhosis.Journal of Hepatology 2018; 69: 406-460.

337 27. Runyon BA, AASLD. Introduction to the revised American Association for the study 338 of liver diseases practice guideline management of adult patients with ascites due to 339 cirrhosis 2012. Hepatol Baltim Md. (2013) ;57:1651-1653

340 28. Jenne CN, Liao S, Singh B. Neutrophils: multitasking first responders of immunity 341 and tissue homeostasis. Cell Tissue Res 2018;371(3):395-397.

342 29. Gibson C, Berliner N. How we evaluate and treat neutropenia in adults. Blood $343 \quad 2014 ; 124(8): 1251-8$.

344 30. Shapiro MF, Greenfield S. The complete blood count and leukocyte differential 345 count: an approach to their rational application. Ann Intern Med1987;106:65-74.

346 31. Alfar M, Abd El-Maksoud M, Mousa N. B-cell monoclonal lymphocytosis in chronic 347 hepatitis C virus infection. Med J Viral Hepatitis 2018;3:27-35.

348 32. Lee JH, Song S, Yoon SY, Lim CS, Song JW, Kim HS.. Neutrophil to lymphocyte 349 ratio and platelet to lymphocyte ratio as diagnostic markers for pneumonia severity. $\mathrm{Br} J$ 350 Biomed Sci 2016;73(3):140-142.

351 33. Mousa N, Besheer T, Abdel-Razik A, Hamed M, Deiab AG, Sheta T, et al. Can 352 combined blood neutrophil to lymphocyte ratio and C-reactive protein be used for 353 diagnosis of spontaneous bacterial peritonitis?.Br J Biomed Sci 2018;75(2):71-75. 
354 34. Abdel-Razik A, Mousa N, Besheer TA, Eissa M, Elhelaly R, Arafa M, et al. 355 Neutrophil to lymphocyte ratio as a reliable marker to predict insulin resistance and 356 fibrosis stage in chronic hepatitis C virus infection. Acta Gastroenterol Belg 2015; 357 78:386-392.

358 35. Shi KQ, Fan YC, Ying L, Lin XF, Song M, Li LF, et al. Risk stratification of 359 spontaneous bacterial peritonitis in cirrhosis with ascites based on classification and 360 regression tree analysis. Mol Biol Rep 2012;39:6161-6169.

361 36. Schwabl P, Bucsics T, Soucek K, Mandorfer M, Bota S, Blacky A, et al. Risk factors 362 for development of spontaneous bacterial peritonitis and subsequent mortality in cirrhotic 363 patients with ascites. Liver Int 2015; 35 (9): 2121-8.

364 37. Rimola A, Garcia-Tsao G, Navasa M, Piddock LJ, Planas R, Bernard B, et al. 365 Diagnosis, treatment and prophylaxis of spontaneous bacterial peritonitis: a consensus 366 document. International Ascites Club. J Hepatol 2000;32:142-153.

367

368

369

370

371

372

373

374

375

376

377

378

$379 \quad 1$. 
380 Table 1. Clinical and biochemical characteristic of studied patient.

381

382

\begin{tabular}{|c|c|c|c|}
\hline Parameters & $\begin{array}{l}\text { SBP (Case) } \\
(\mathrm{N}=300)\end{array}$ & $\begin{array}{l}\text { Non-SBP (Control) } \\
(\mathrm{N}=\mathbf{3 0 0})\end{array}$ & P value \\
\hline Age & $55.60 \pm 8.44$ & $55.36 \pm 7.78$ & 0.29 \\
\hline $\operatorname{Sex}(M / F)$ & $207 / 93$ & $194 / 106$ & 0.14 \\
\hline $\mathrm{HCV}(\mathrm{N} / \%)$ & $273(91 \%)$ & $275(91.6 \%)$ & 0.66 \\
\hline HBV (N/\%) & $15(5 \%)$ & $17(5.6 \%)$ & 0.71 \\
\hline NASH $(\mathrm{N} / \%)$ & $8(2.6 \%)$ & $5(1.6 \%)$ & 0.4 \\
\hline Cryptogenic (N/\%) & $4(1.3 \%)$ & $3(1 \%)$ & 0.7 \\
\hline Fever $(\mathrm{N} / \%)$ & $126(37.3 \%)$ & 0 & $<0.001$ \\
\hline Abdominal pain (N\%) & $201(67 \%)$ & $115 / 300$ & $<0.001$ \\
\hline Albumin (g/dl) & $2.36 \pm 0.61$ & $2.41 \pm 0.62$ & 0.25 \\
\hline Bilirubin (mg/dL) & $3.30(1.80-6.30)$ & $0.90(0.70-4.10)$ & $<0.001$ \\
\hline ALT (U/L) & $30.0(20.25-42.00)$ & $36.0(20.0-56.0)$ & 0.006 \\
\hline AST (U/L) & $61.0(37.0-96.0)$ & $31.0(22.0-95.0)$ & $<0.001$ \\
\hline Creatinine (mg/dl) & $1.5(0.9-2.4)$ & $1.4(0.8-1.6)$ & 0.003 \\
\hline PT (seconds) & $13.9 \pm 2.8$ & $13.4 \pm 2.6$ & 0.023 \\
\hline CRP (mg/dl) & $48.0(44.0-48.0)$ & $7.0(5.0-9.0)$ & $<0.001$ \\
\hline Platelets $\left(10^{9} / \mathrm{L}\right)$ & $79(46-139)$ & $93(59-112)$ & 0.006 \\
\hline Blood WBC (10 $3 / \mathrm{cmm})$ & $8.13 \pm 3.23$ & $4.88 \pm 1.60$ & $<0.001$ \\
\hline $\mathrm{ANC}\left(10^{3} / \mathrm{cmm}\right)$ & $5.98 \pm 2.86$ & $2.25 \pm 0.6$ & $<0.001$ \\
\hline $\begin{array}{ll}\text { Blood lymphocyte } \\
\left(10^{3} / \mathrm{cmm}\right)\end{array}$ & $1.66 \pm 0.79$ & $1.64 \pm 0.89$ & 0.77 \\
\hline Haemoglobin (g/dl) & $10.10 \pm 1.87$ & $10.05 \pm 2.11$ & 0.57 \\
\hline
\end{tabular}

383

$384 \mathrm{HCV}$, hepatitis $\mathrm{C}$ virus; HBV, hepatitis B virus; NASH, non-alcoholic steatohepatitis ;

385 ALT, alanine aminotransferase; AST, aspartate aminotransferase; PT, prothrombin

386 time;WBC, white blood cells; CRP, C reactive protein; ANC,Absolute neutrophil count.

387

388

389

390

391 
392 Table 2. Logistic regression analysis of risk factors associated with SBP.

\begin{tabular}{|l|l|l|l|l|}
\hline Parameters & \multicolumn{3}{|c|}{$\begin{array}{l}\text { 95\% CI } \\
\text { Lower- } \\
\text { Upper }\end{array}$} & Sig. \\
\hline Bilirubin & 1.002 & 0.911 & 1.102 & 0.969 \\
\hline AST & 0.993 & 0.983 & 1.002 & 0.137 \\
\hline ALT & 1.003 & 0.990 & 1.015 & 0.701 \\
\hline Creatinie & 0.320 & 0.182 & 0.563 & 0.000 \\
\hline Platelets & 1.05 & 0.975 & 1.533 & 0.011 \\
\hline CRP & 0.761 & 0.000 & 1.03 & 0.009 \\
\hline Blood WBC & 1.9 & 0.999 & 2.65 & 0.001 \\
\hline ANC & 0.946 & 0.913 & 0.980 & 0.002 \\
\hline
\end{tabular}

393

394

395

396

397

398

399

400

401

402

403

404

405

406

407

408

409

410

411

412

413

414

415

416

417

418

419

420

421

422

423 
Table 3. Comparison between culture positive and culture negative patients with SBP.

\begin{tabular}{|c|c|c|c|}
\hline Parameters & $\begin{array}{l}\text { Culture Positive } \\
\text { SBP }(N=184)\end{array}$ & $\begin{array}{l}\text { Culture Negative } \\
\text { SBP }(\mathrm{N}=116)\end{array}$ & $P$ value \\
\hline Age & $54.81 \pm 7.53$ & $56.86 \pm 9.82$ & 0.02 \\
\hline Abdominal pain (N/\%) & $128(69.5 .9 \%)$ & $73(62.9 \%)$ & 0.23 \\
\hline Fever $(\mathrm{N} / \%)$ & $73(39.67 \%)$ & $53(45.6 \%)$ & 0.30 \\
\hline Albumin (g/dl) & $2.42 \pm .65$ & $2.34 \pm .59$ & 0.5 \\
\hline Bilirubin (mg/dl) & $3.5(2.0-5.05)$ & $3.3(1.80-7.1)$ & 0.36 \\
\hline $\operatorname{ALT}(\mathrm{U} / \mathrm{L})$ & $48(33-74)$ & $48(36.5-80.5)$ & 0.53 \\
\hline $\operatorname{AST}(\mathbf{U} / \mathbf{L})$ & $33(20-37)$ & $29(21-43)$ & 0.17 \\
\hline Creatinine (mg/dl) & $1.5(0.9-2.4)$ & $1.4(0.8-1.6)$ & 0.003 \\
\hline INR & $1.73 \pm 0.53$ & $1.60 \pm 0.51$ & 0.14 \\
\hline CRP (mg/dl) & $48(12-96)$ & $47(24-48)$ & 0.02 \\
\hline $\begin{array}{l}\text { Platelets }\left(10^{9} / \mathrm{L}\right) \\
\text { Min-max }\end{array}$ & $\begin{array}{l}72.5(46-128) \\
(12-210)\end{array}$ & $\begin{array}{l}97(45.7-157.2) \\
(10-41)\end{array}$ & 0.001 \\
\hline Blood WBC (10 $/ \mathrm{cmm})$ & $8.79 \pm 3.7$ & $7.80 \pm 3.28$ & 0.008 \\
\hline $\mathrm{ANC}\left(10^{3} / \mathrm{cmm}\right)$ & $6.54 \pm 3.0$ & $5.64 \pm 2.6$ & 0.003 \\
\hline $\begin{array}{ll}\text { Blood } & \text { lymphocytes } \\
\left(10^{3} / \mathrm{cmm}\right) & \\
\end{array}$ & $1.4 \pm 0.19$ & $1.6 \pm 0.23$ & 0.5 \\
\hline Haemoglobin (g/dl) & $10.24 \pm 2.15$ & $10.05 \pm 1.67$ & 0.20 \\
\hline
\end{tabular}


447 Table 4. Logistic regression analysis of risk factors associated with culture positive SBP.

\begin{tabular}{|l|l|l|l|l|}
\hline Parameters & Exp (B) & \multicolumn{2}{|c|}{$\begin{array}{c}\text { 95\% CI } \\
\text { Lower-Upper }\end{array}$} & Sig. \\
\hline Age & 1.030 & 0.972 & 1.091 & 0.314 \\
\hline Creatinie & .976 & 0.672 & 1.418 & 0.898 \\
\hline Platelets & 0.921 & 0.901 & 1.77 & 0.016 \\
\hline WBCs & .999 & 0.922 & 1.45 & 0.001 \\
\hline ANC & 1.081 & 1.036 & 1.127 & 0.001 \\
\hline
\end{tabular}

448

449

450

451

452

453

454

455

456

457

458 


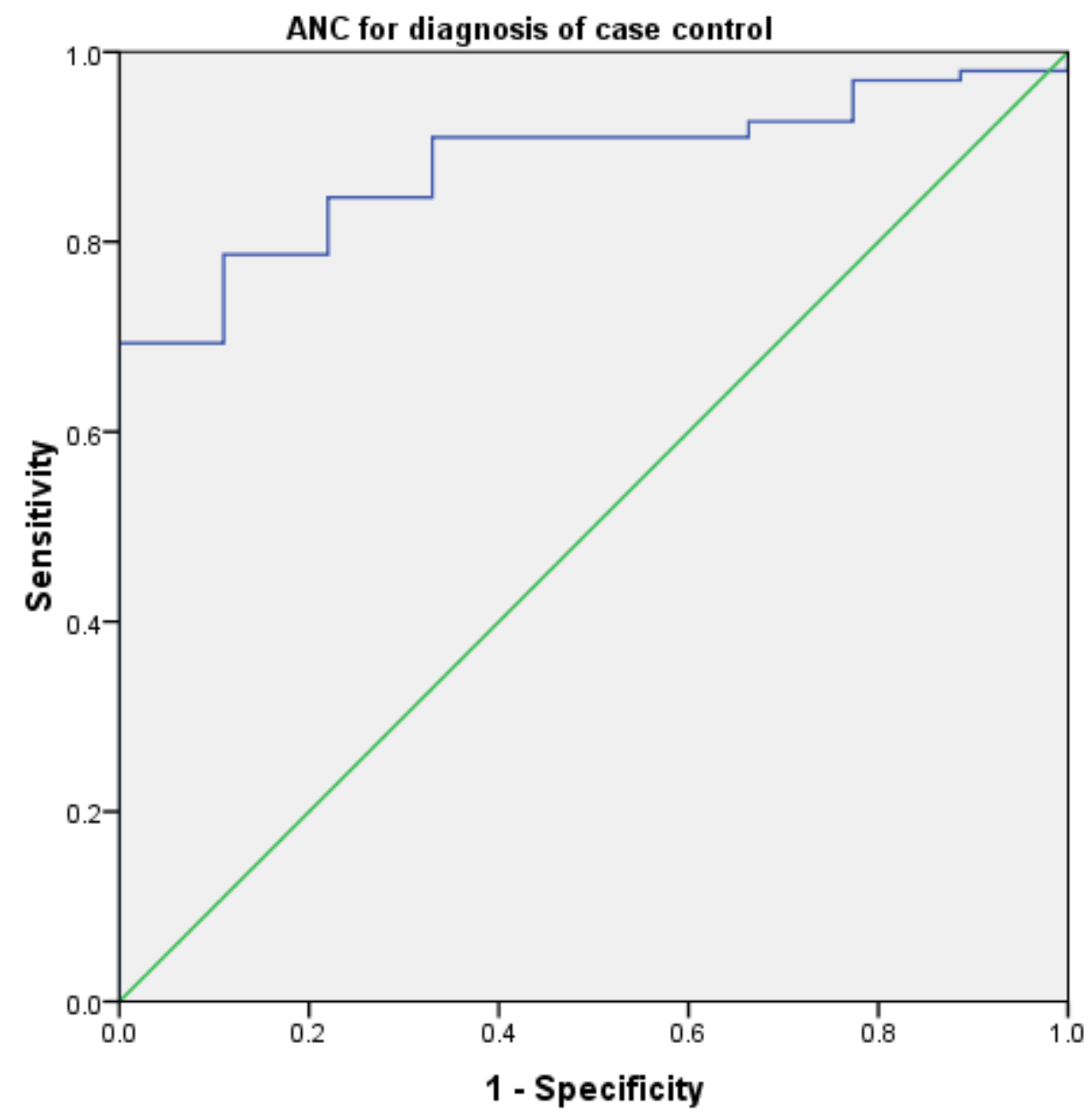

459

460

461 Figure 1. Receiver operator characteristics curve for blood absolute neutrophil count in 462 cases of spontaneous bacterial peritonitis (case control).

463

464

465 


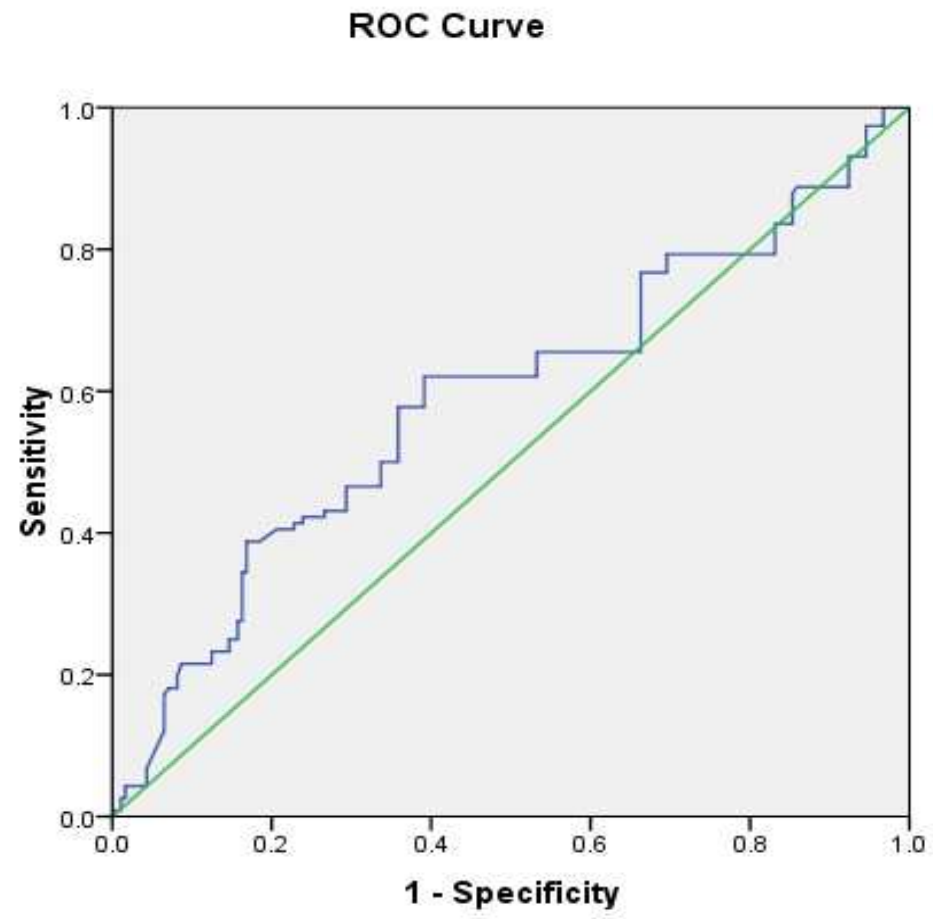

466

467

468 Figure 2. Receiver operator characteristics curve for blood absolute neutrophil count in 469 culture-positive and culture negative spontaneous bacterial peritonitis.

470

471 